International Journal of Linguistics, Literature and Culture
Available online at https://sloap.org/journals/index.php/ijllc/
Vol. 5, No. 4, July 2019, pages: 34 45
ISSN: 2455-8028
https://doi.org/10.21744/ijllc.v5n4.699

\title{
Permanent Application of Diagnostic Assessment on Learning Teaching Process
}

CrossMark

CrossMark

\author{
Darwin Gustavo Lucas Delgado a \\ Freddy Eduardo Anchundia Delgado ${ }^{b}$ \\ Pamela Mariana Zambrano Quiroz ${ }^{c}$
}

Article history:

Received: 27 March 2019

Accepted: 31 May 2019

Published: 31 July 2019

\section{Keywords:}

decision-making;

diagnostic;

evaluation;

feedback;

learning teaching,

\begin{abstract}
This article is an analysis of the application of diagnostic assessment in teaching processes - learning by teachers at the School of Basic Education "May 24" in the canton of Portoviejo, for this purpose, exploratory research was used, to do so, to use exploratory research, to determine quantitative and qualitative criteria and achieve learning directed to the development of the evaluated body, as well as the application of the survey as a technique for collecting relevant data from the object of the study, this study shows that evaluation as a diagnostic process will allow the identification of previous learnings that will mark the starting point and decision-making for new learning, where the teachers apply it only at the beginning of the school year, limiting an educational practice of quality and warmth through modifications that respond to needs regarding the level of student performance, however different authors determine that this type of evaluation it should be used at the beginning of a topic or an academic period, becoming a permanent practice and accompanied by feedback processes.
\end{abstract}

2455-8028 ${ }^{\circledR}$ Copyright 2019. The Author. This is an open-access article under the CC BY-SA license (https://creativecommons.org/licenses/by-sa/4.0/) All rights reserved.

\section{Author correspondence:}

Darwin Gustavo Lucas Delgado,

Pontificia Universidad Católica del Ecuador Sede Manabí, Portoviejo, Ecuador.

Email address: dlucas8841@pucem.edu.ec

\section{Introduction}

Diagnostic evaluation is treated by many authors, this is a question of many answers that justifies the existence and need of an evaluator process, centered on students. To imagine the teaching and learning processes without evaluation, it is like following a path to reach a certain place, but without looking at the indicators that indicate

\footnotetext{
a Pontificia Universidad Católica del Ecuador Sede Manabí, Portoviejo, Ecuador

b Pontificia Universidad Católica del Ecuador Sede Manabí, Portoviejo, Ecuador

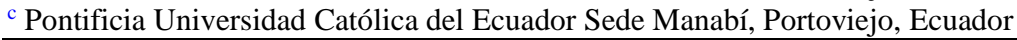


whether you are going the right way; discover that you get to another unwanted place, or that you meet the goal, but having used the more complicated path, because it was not observed that there was another shorter and better fit.

In fact, teachers at the Educational Institution where the research study was conducted, use the diagnostic evaluation at the beginning of each school year, to identify the levels of competencies they present and show students when they start any allowing it to develop a learning-teaching process planning and guide it to the needs of each of the students.

This evaluation is the start to organize educational activities throughout the school year, which establishes a plan for the competencies to be worked on and serves to detect the specific needs of the students, among the other actions of educational intervention, thus providing the basis for many important judgments that are issued throughout the school year.

The main agent for the conduct of the diagnostic evaluation is the teacher, from the knowledge he has of the students can design, organize, coordinate, guide and follow up the actions and activities to be carried out in the classroom to achieve the know the needs, the difficulties students face and their chances to achieve the goal. The evaluation allows the teacher to collect evidence that serves to monitor the progress of his students, make observation records to integrate him into the record, where all the information regarding his personal history is located.

Another element that the teacher has to carry out the evaluation of the children are the thoughts that they convey of the difficulties presented in the development of the activities, suggestions or tastes for certain activities. The elements that parents provide about the advances they detect in their children, the actions that the school undertakes; are criteria for reviewing the ways of functioning, school organization and classroom work.

\section{Materials and Methods}

The research on the permanent application of diagnostic evaluation in the teaching-learning process was carried out at the School of General Basic "24 de Mayo" in the canton of Portoviejo, with 38 teachers of the different levels offered by the Institution Educational.

Exploratory research was used to inform the educational reality regarding the application of the permanent diagnostic evaluation during the development of the educational process at the sublevels that make up the level of Basic General Education. In addition, the survey was used as a research technique, which was applied to teachers, to collect relevant data of the object of the study, and through the analytical method, the information obtained was interpreted in order to establish the conclusions.

\section{Results and Discussions}

\subsection{Conceptualization of diagnostic evaluation}

The assessment is an assessment tool that controls, verifies compliance, develops skills and knowledge necessary to identify the reality of students, with structured objective elements, such as direct observation, argumentation, question technique, exploring or recognizing the reality of the educational fact, compared to the initial results of the diagnostic test, applying the information obtained for correct decision-making

The term Diagnostic Assessment aims to mark the conditions and possibilities of initial apprenticeships or systematic and rigorous execution that is done at the beginning of a school year, a topic or an academic period, detecting needs and promoting those aspects or elements that support a quality educational practice through modifications that respond to needs regarding the level of student performance, educational institution and educational system. According to Orozco (2006), it is necessary to obtain an individualized information, use various evaluation tools. The evaluation should permanently gather concrete evidence of learning with data relating to various situations, not focusing on tests, but on class dynamics.

Learning does not depend only on the teacher, according to Ramsden (1992), it can be corroborated that without the effort of students learning is not possible, as a resource to improve the innovative educational quality, which response to the needs of students, being competent training in the face of the new requirements of schools.

Delgado, D. G. L., Delgado, F. E. A., \& Quiroz, P. M. Z. (2019). Permanent application of diagnostic assessment on learning teaching process. International Journal of Linguistics, Literature and Culture, 5(4), 34-45. 


\subsection{Purposes or purposes of diagnostic or initial evaluation}

The evaluation allows to obtain the real and systematic information to have data that allow knowing and issue evaluation reports, leading the teacher to be the guide of learning, not depending only on him; is formed alongside the responsibility and dedication of the students, which without the effort is not possible. As a resource to improve the innovative educational quality used in the diagnostic assessment that responds to the needs of students, as it says (Navarro et al., 2017).

Teachers must demonstrate the level of understanding of their students, disseminate among them the need to know their own progress and development, are evidenced by the assessment that does not point out, or divide students who do not master knowledge. The purpose of the evaluation is not to show the teacher's knowledge in the deficiencies of some students, knowing that good evaluation helps teachers to teach better, to know the obstacles that the student has to overcome, they can stimulate, accompany ingenuity and ensure the understanding that leads to learning, what is evaluated and what is evaluated in the diagnosis, these are two inextricably linked elements.

The delimitation of purpose requires the definition of the object of evaluation, which aims to make decisions at the beginning of the school year, so that the student knows his progress, to predict the development of the students as mentioned (Martínez, 2012).

Diagnostic evaluation as a curriculum process helps to gain information about the learnings achieved and make decisions to continue; the purpose of the evaluation is to improve educational outcomes, establishing the actual level of knowledge of the student before starting a stage of the teaching-learning process, depending on their academic history, identifying the prior knowledge of a new apprenticeship, designing remedial activities oriented to leveling, objectively planning the adjustments or modifications to follow. Establish reasonable goals to make value judgments on school achievements and thereby adapt pedagogical treatment to the characteristics and peculiarities of students.

\subsection{Characteristics of diagnostic assessment}

The diagnostic evaluation should have the following characteristics shown in Figure 1. 


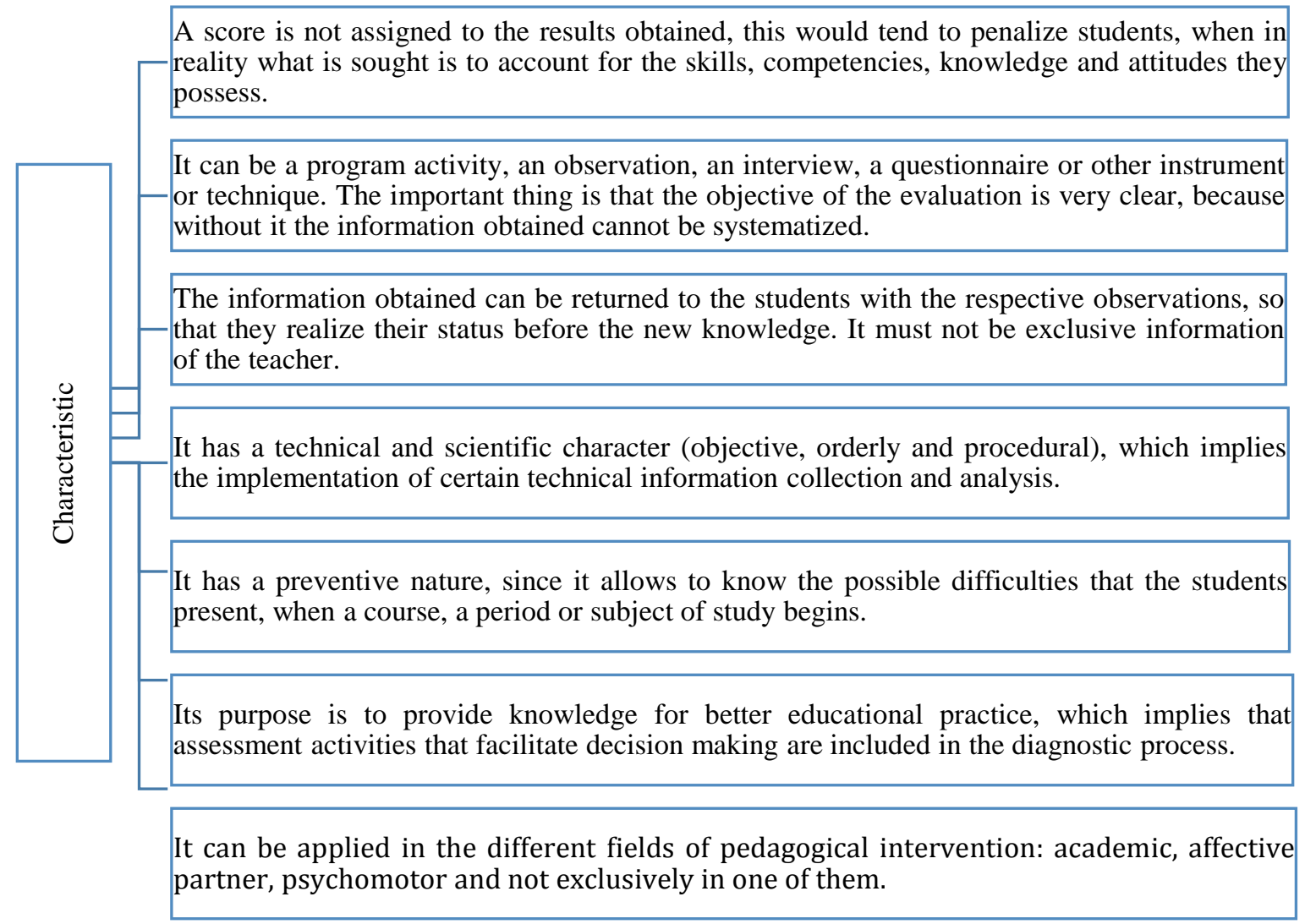

Figure 1. Diagnostic Assessment Features

Source: (Bolaño, 2010).

Diagnostic evaluation is an evaluative instance, in which it must be initiated in any learning process, does not carry quantitative qualification, because it will tend to penalize students and the diagnostic function of the evaluation will be lost, when what in is actually sought is to know what they know at the beginning of a learning unit. It is only possible to rate a state of progress when a teaching-learning process has already been carried out. It is dynamic because part of a real situation to reach the ideal, it allows to use various tools to collect the information, which is a time period analyzes the results of its application.

\subsection{Why the diagnostic evaluation is done}

The diagnostic evaluation is done to check the level at which students are achieving the competencies, to support the decision-making about the learnings that will receive the most attention in the following days, also allows to determine how it should be designed teaching situations for students to successfully achieve purposes. It is done to improve, solve learning difficulties and above all contributes to the development of basic competencies, solving problems (Trujillo, 2012).

The diagnostic evaluation is intended to determine the following as shown in Figure 2.

Delgado, D. G. L., Delgado, F. E. A., \& Quiroz, P. M. Z. (2019). Permanent application of diagnostic assessment on learning teaching process. International Journal of Linguistics, Literature and Culture, 5(4), 34-45. 


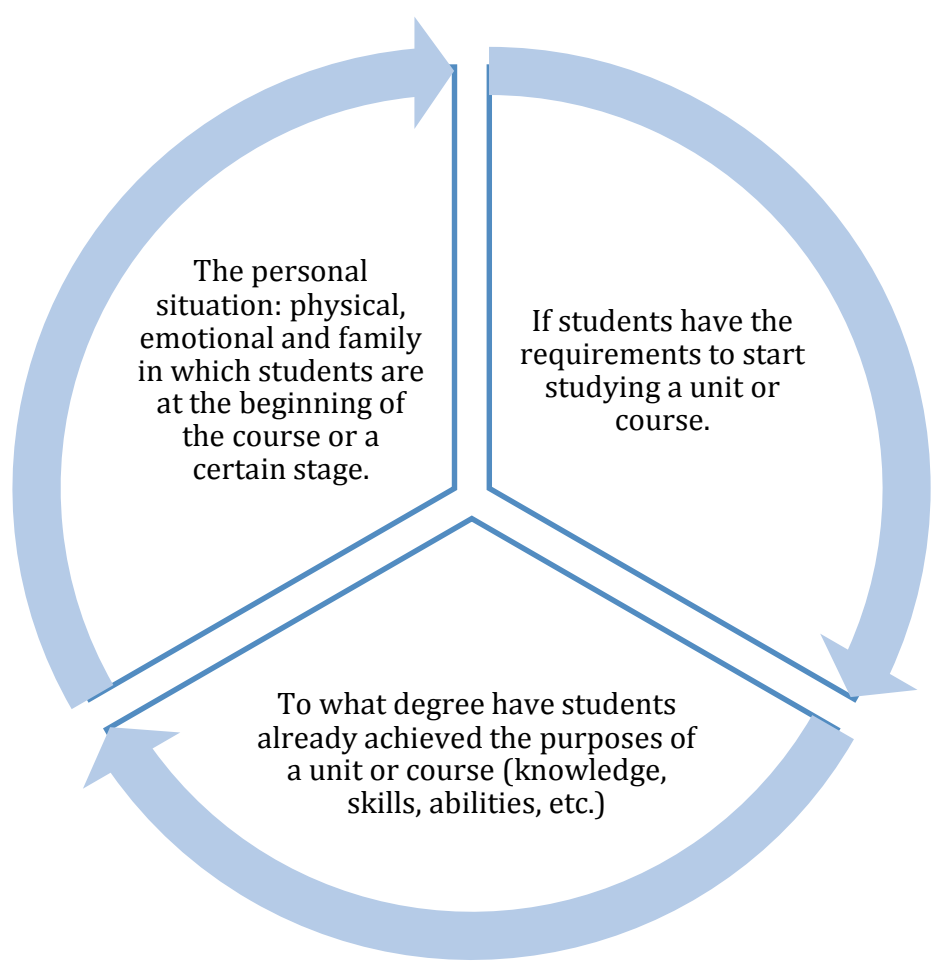

Figure 2. Aspects of Diagnostic Assessment Source: Jorba \& Sannmartí (1997)

The teacher needs to take into account the basic background before performing any pedagogical intervention that took place at the beginning of the course or also at the beginning of each unit. Diagnosis allows a better approach to the contents and competences of students and promotes teaching processes more adjusted to the needs of them (Bombelli, 2012).

\subsection{The objectives of the diagnostic assessment}

Before mentioning the objectives pursued by the diagnostic evaluation, it is necessary to start from its definition from the legal basis, for the Ministry of Education in the General Regulations to the Organic Law of Intercultural Education (LOEI) in its Article 186. stipulates that the diagnostic evaluation applies at the beginning of an academic period to be a degree, course, chimerism or unit of work with the aim of knowing the previous knowledge with which the student enters the learning process (Mineduc, 2017).

In addition, diagnostic evaluation investigates the previous knowledge that students have and have acquired with experiences of their lives outside or inside the classroom, in order to identify and develop skills that will be essential for performance Academic. So the goal of this type of evaluation is not to obtain a grade, rather with the results achieved to make modifications to optimize the teaching process - learning, taking into account the conditions of the students and adjust the work (Drago, 2017).

Figure 3 shows the objectives pursued by diagnostic evaluation in terms of learning situations. 


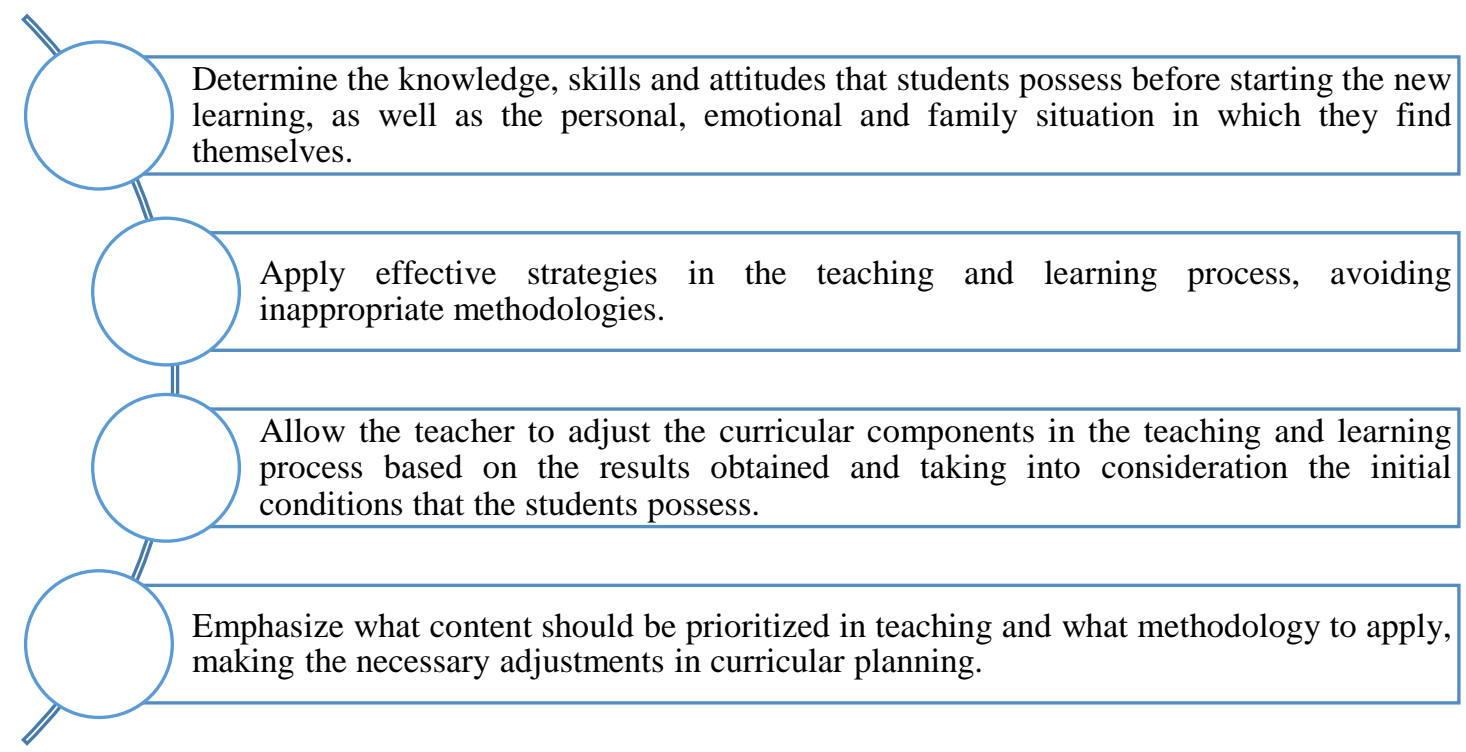

Figure 3. Objectives of diagnostic evaluation

Source: (Nuñez y Quiñones, 2012)

\section{Techniques and instruments for a diagnostic assessment}

In classrooms there are several types of students with different learning styles, knowing them and using this information for the benefit of the teaching process - learning is key to training critical, thoughtful and supportive students, to this is done, the diagnostic evaluation is carried out.

It is important to know the techniques and evaluation tools in the educational processes, the same that makes it easier for the teacher to carry out the evaluation of learnings in an objective and fairway. Figure 4 details several types of evaluation techniques and instruments proposed by Casanova in a chapter called the evaluator model and its methodology of the book Manual de Evaluation (Casanova, 1998).

Delgado, D. G. L., Delgado, F. E. A., \& Quiroz, P. M. Z. (2019). Permanent application of diagnostic assessment on learning teaching process. International Journal of Linguistics, Literature and Culture, 5(4), 34-45. 


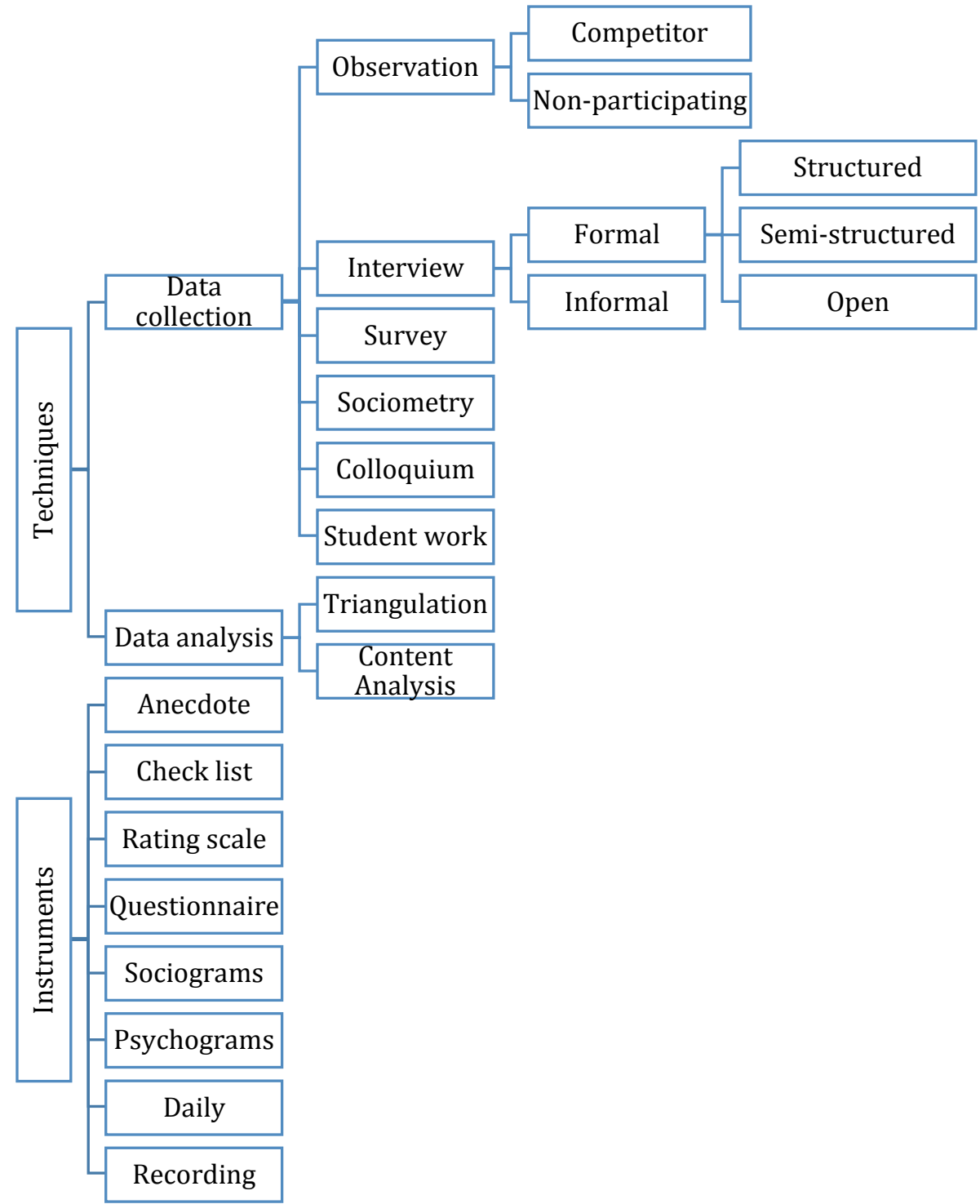

Figure 4. Evaluation techniques and instruments Source: (Casanova, 1998)

Other authors establish means, techniques, and instruments that are applied for a diagnostic evaluation, in Figure 5 it is shown in a very clear and precise way. 


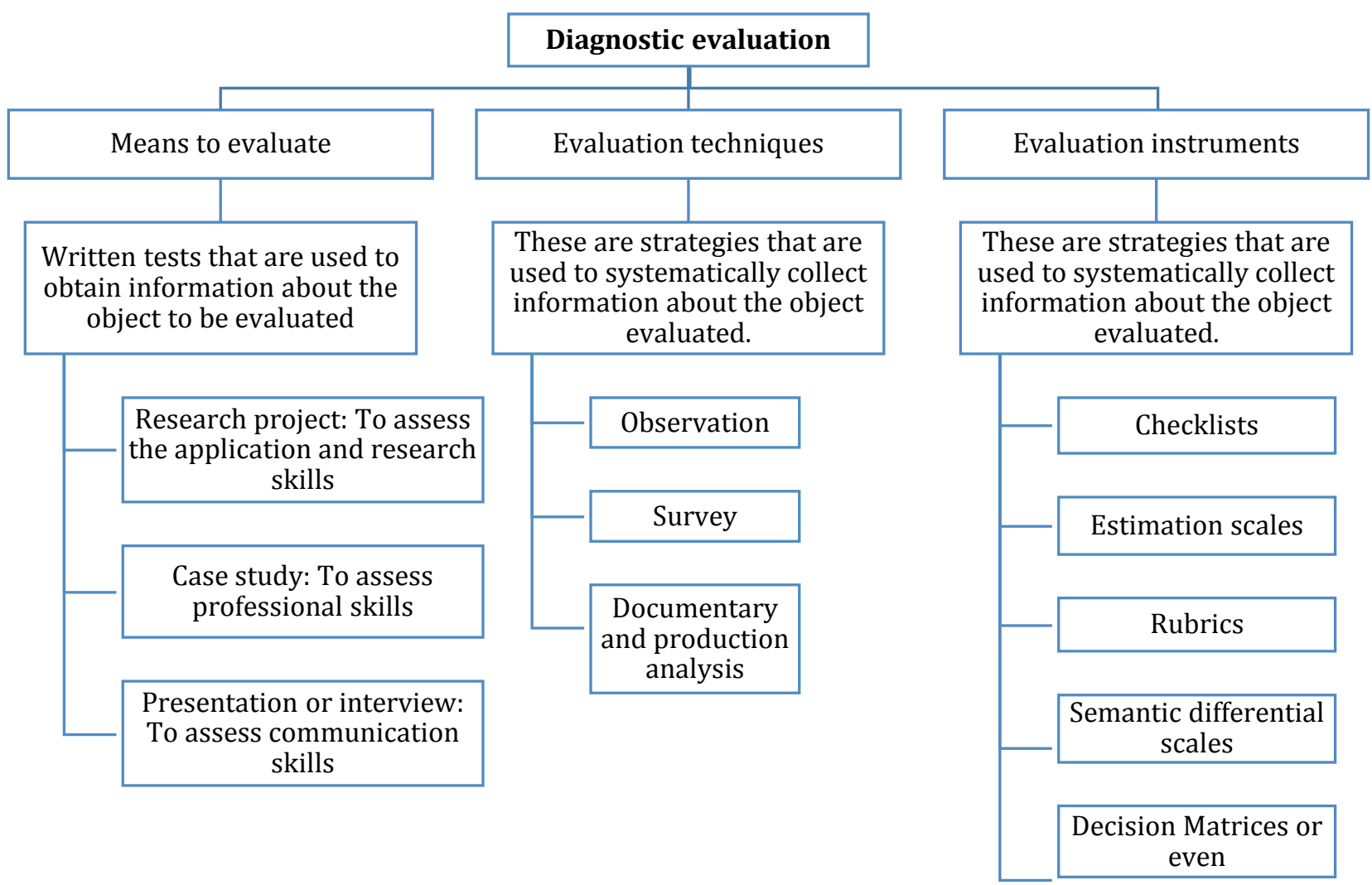

Figure 5. Means, techniques and evaluation tools Source: (Rodríguez \& Ibarra, 2011)

\section{Feedback on diagnostic evaluation processes}

Feedback is the pivot on which the assessment is based, because from this process the teacher and students interact and meditate on the experiences that occur in the learning process, so that students self-regulate, re-evaluate progress, challenges and concrete opportunities to improve, therefore, the development of effective feedback allows the student to reflect on their activities in the process to achieve the goals and objectives set, correcting errors and generating a benchmark for general evaluation (Diaz, 2018).

Therefore, the feedback applied to the evaluation and the educational process represents a method of vital importance, because it allows to gather information on the learning of a given topic, becoming a very useful tool when analyzing the teaching and learning process, recognizing successes and mistakes in order to ensure success in the training of students. Therefore, it is relevant not to reduce the results obtained from an evaluation to a simple rating, on the contrary, to use that information as a starting point to identify weaknesses and turn them into strength.

After conducting the documentary review of several investigative papers on diagnostic evaluation and having applied the research at the School of Basic Education "May 24" on this topic, it is determined that diagnostic evaluation is a process that runs at the beginning of an academic period to know the preconditions with which the student begins learning, this conceptualization most of the teachers involved know it, in table 1 it is evident that they mostly possess knowledge of the diagnostic evaluation according to the General Regulations to the Organic Law on Intercultural Education and in relation to other types of evaluation such as the formative and summative.

Delgado, D. G. L., Delgado, F. E. A., \& Quiroz, P. M. Z. (2019). Permanent application of diagnostic assessment on learning teaching process. International Journal of Linguistics, Literature and Culture, 5(4), 34-45. 
Table 1

Conceptualization of diagnostic assessment

\begin{tabular}{lll}
\hline Options & Frequency & Percentage (\%) \\
\hline $\begin{array}{l}\text { Determines the preconditions with which the student } \\
\text { enters the learning process }\end{array}$ & 29 & 76,30 \\
$\begin{array}{l}\text { It is done to assign a totalizing assessment that reflects the } \\
\text { proportion of learning achievements achieved }\end{array}$ & 8 & 21,10 \\
$\begin{array}{l}\text { It is done during the learning process to allow the teacher } \\
\text { to make adjustments to the teaching methodology }\end{array}$ & 1 & 2,60 \\
\hline
\end{tabular}

It was also investigated with what continuity teachers apply diagnostic assessment in the learning-teaching process, Table 2 indicates that a large percentage of them only apply this type of assessment at the beginning of the school year, no longer being a process Permanent.

Table 2

Application of diagnostic assessment

\begin{tabular}{lll}
\hline Options & Frequency & Percentage (\%) \\
\hline At the start of the year of the year & 34 & 69,40 \\
By starting a partial & 4 & 8,20 \\
When Starting a Teaching Unit & 5 & 10,20 \\
When you start a new topic & 6 & 12,20 \\
\hline
\end{tabular}

In addition, the study found that teachers use a variety of tools to perform diagnostic evaluation, from the use of a test or questionnaire, as well as a written work type trial as detailed in Table 3, but certainly the technique that the greatest use is the observation of the teacher, in this sense, to carry out a good diagnostic evaluation it is necessary to combine tools for the evaluation to achieve its purposes, it is essential to make an appropriate selection of the instruments that will be (Covacevich, 2014).

Table 3

Use of the types of tools for diagnostic evaluation

\begin{tabular}{llll}
\hline Evaluation instruments & Options & Frequency & Percentage (\%) \\
\hline \multirow{4}{*}{ A written work (e.g. an } & At least once a day & 9 & 23,70 \\
essay) & At least once a week & 14 & 36,80 \\
& Once a month & 6 & 15,80 \\
& Once or twice a year & 3 & 7,90 \\
& Never & 6 & 15,80 \\
Short tests and quizzes during & At least once a day & 10 & 26,30 \\
classes & At least once a week & 12 & 31,60 \\
& Once a month & 9 & 23,70 \\
& Once or twice a year & 4 & 10,50 \\
& Never & 3 & 7,90 \\
Professor's observation & At least once a day & 26 & 68,40 \\
& At least once a week & 5 & 13,20 \\
& Once a month & 4 & 10,50 \\
& Once or twice a year & 1 & 2,60 \\
& Never & 2 & 5,30 \\
Feedback on understanding & At least once a day & 18 & 47,40 \\
& At least once a week & 5 & 13,20 \\
& Once a month & 5 & 13,20 \\
& Once or twice a year & 5 & 13,20 \\
& Never & 5 & 13,20 \\
\hline
\end{tabular}


Finally, in Table 4, it is revealed that when negative results are obtained from a diagnostic evaluation, teachers proceed to make a feedback, because through this process the teacher and students interact in order to meditate on the experiences that occur in the evaluation process, the same that allows the student a reflection on the action of their learning process to achieve the goals and objectives set, correcting errors and generating a benchmark to improve.

Table 4

Teacher actions after diagnostic evaluation

\begin{tabular}{lll}
\hline Options & Frequency & Percentage $(\%)$ \\
\hline Make adjustments to your micro-planning & 9 & 23.70 \\
Submit reports & 4 & 10.50 \\
Feedback & 24 & 63.20 \\
Continue the new theme of study & 1 & 2.60 \\
\hline
\end{tabular}

\section{Conclusion}

The diagnostic evaluation should be used both when starting a topic or unit, as well as at the beginning of the school year, because this process obtains information about the previous knowledge, skills, and competencies with which students begin a new apprenticeship, with the aim of leveling them to achieve the required learnings and the proposed objectives.

Also, teachers from the Educational Unit "May 24" although they know that the diagnostic evaluation is permanent as stated in the Regulation to the LOEI, they only use it at the beginning of the school year, and to a large extent to know the previous knowledge of the studies as a starting point and decision-making point in the teachinglearning process.

Finally, when the negative results of a diagnostic evaluation are obtained, teachers carry out feedback processes, with the aim of recognizing the successes and errors to ensure the success of the training of the students, in addition share the results with the management team, to adjust the planning and adapt them to the needs of the group.

\section{Conflict of interest statement}

The authors declared that they have no competing interest.

\section{Statement of authorship}

The authors have a responsibility for the conception and design of the study. The authors have approved the final article.

\section{Acknowledgments}

The authors would like to thank the editor of IJJLC for their valuable time, support, and advice in completing the current study.

Delgado, D. G. L., Delgado, F. E. A., \& Quiroz, P. M. Z. (2019). Permanent application of diagnostic assessment on learning teaching process. International Journal of Linguistics, Literature and Culture, 5(4), 34-45. 


\section{References}

Bolaños, G. (2010). Diagnostic Assessment. https://es.slideshare.net/Socialesdigital/evaluacin-diagnstica-3577084

Bombelli, E. (2012). The importance of diagnostic evaluation in higher-level subjects with pre-university knowledge. GPT Magazine People Management and Technology, 5(13)https://dialnet.unirioja.es/descarga/articulo/4125245.pdf

Casanova, M. (1998). Educational evaluation manual. Basic school. http://formacion.sigeyucatan.gob.mx/formacion/materiales/4/4/d2/p3/3\%20la.evaluacion.educativa.educacion.bas ica.pdf

Covacevich, C. (2014). How to select an instrument to evaluate student learning. https://publications.iadb.org/publications/spanish/document/C\%C3\%B3mo-seleccionar-un-instrumento-paraevaluar-aprendizajes-estudiantiles.pdf

Diaz, M. (2018). Impact of feedback and formative assessment on biosciences teaching-learning. Higher Medical Education, 32(3). http://ems.sld.cu/index.php/ems/article/view/1492/697

Drago, C. (2017). Teacher Support Handevaluation for Learning. http://www.ucentral.cl/prontus_ucentral2012/site/artic/20170830/asocfile/20170830100642/manual_evaluacion.p df

Jorba, J. \& Sannmartí, N. (1997)."Evaluation as a tool to improve the learning process of the sciences", in Luis del Carmen (coord.): "Teaching and learning the sciences of nature in secondary high school" 155-199. Horsori.

Martínez R. F. (2012). formative assessment of classroom learning in the English and French literature. literature review. Mexican Journal of Educational Research, 17(54), 849875.https://www.redalyc.org/pdf/140/14023127008.pdf

Mineduc-Me, Am (2016). 00020-A. Official Registry 725 of January 3, 2017. Accessed July 12, 2017.

Navarro, N., Falconí, A., \& Espinoza, J. (2017).El Improvement of the process of evaluating students of basic education.University and Society Magazine, 69.http://scielo.sld.cu/scielo.php?script=sci_arttext\&pid=S2218-36202017000400008\&lng=es\&tlng=es.

Nuñez, F. y Quiñones, A. (2012). Importance of evaluation and self-assessment in academic performance. Next area: Journal of the Institute for Higher Education Studies, (16), 93104.https://dialnet.unirioja.es/servlet/articulo?codigo=6398351

Orozco, M. (2006). Diagnostic, formative and summative evaluation in translation teaching. (thesis) Spain.http://gent.uab.cat/marianaorozco/sites/gent.uab.cat.marianaorozco/files/Orozco_evaluacion_2006.pdf

Ramsden, P. (1992). Learning to Teach in Higher Education. London: Routledge. https://www.questia.com/read/103908205/learning-to-teach-in-higher-education

Rodriguez, G. \& Ibarra, M. (2011) e-Evaluation Oriented to Strategic E-Learning in Higher Education. Madrid, Narcea.https://books.google.com.ec/books?id=zPakDwAAQBAJ\&printsec=frontcover\&hl=es\&source=gbs_ge_s ummary_r\&cad=0\#v=onepage \&q\&f=false

Trujillo, F. (2012). And the diagnostic evaluation, what is it for?.https://fernandotrujillo.es/y-la-evaluacion-dediagnostico-para-que-sirve/ 


\section{Biography of Authors}

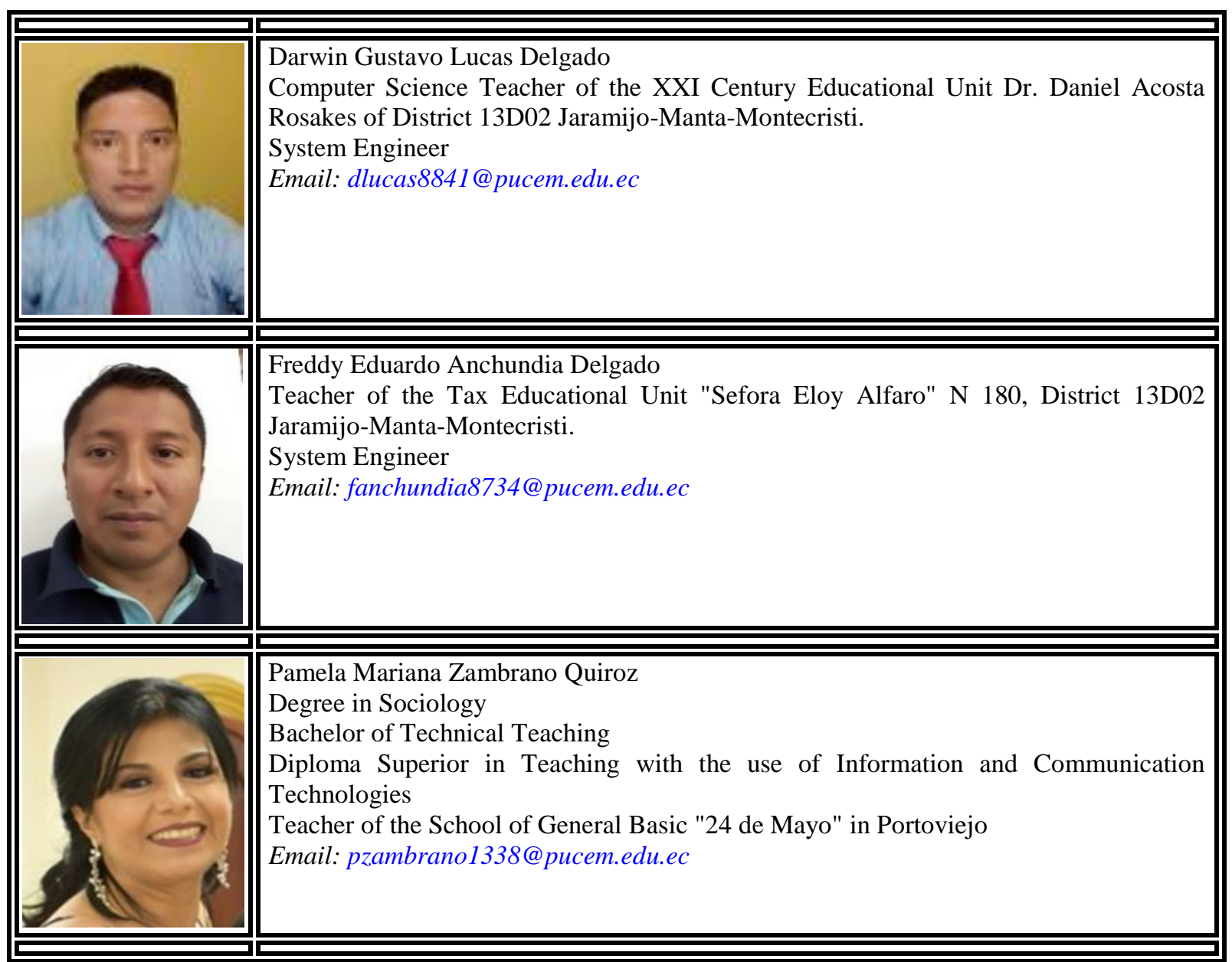

Delgado, D. G. L., Delgado, F. E. A., \& Quiroz, P. M. Z. (2019). Permanent application of diagnostic assessment on learning teaching process. International Journal of Linguistics, Literature and Culture, 5(4), 34-45. https://doi.org/10.21744/ijllc.v5n4.699 